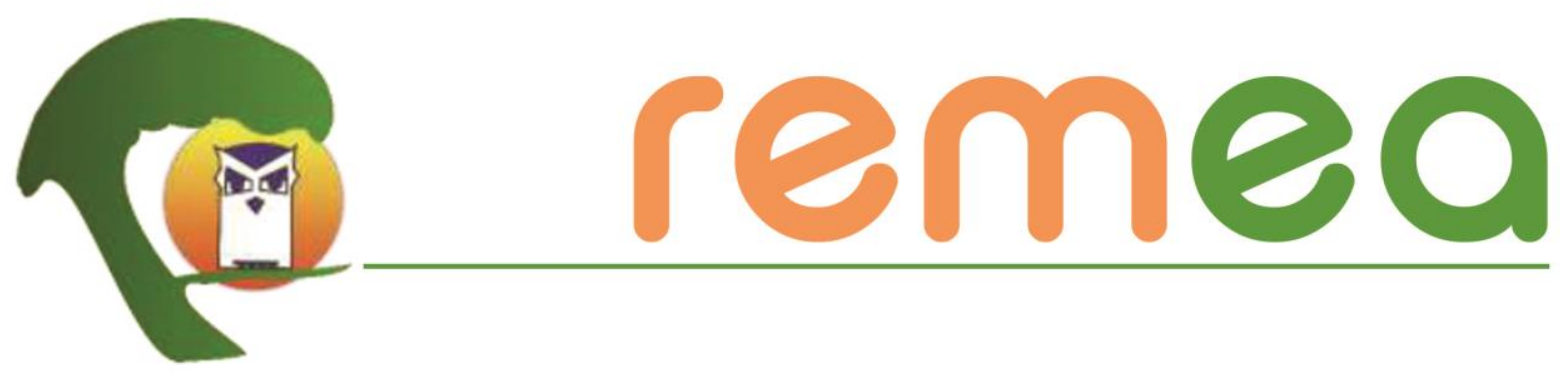

\title{
A abordagem da Educação Ambiental na segunda e na terceira versão da Base Nacional Comum Curricular
}

\author{
Mariana Ferreira Bittencourt ${ }^{1}$ \\ Universidade Estadual do Sudoeste da Bahia \\ ORCID: https://orcid.org/0000-0001-5187-411X \\ Edinaldo Medeiros Carmo ${ }^{2}$ \\ Universidade Estadual do Sudoeste da Bahia \\ ORCID: https://orcid.org/0000-0002-1594-8983
}

Resumo: O presente artigo tem como objetivo analisar a abordagem da Educação Ambiental na segunda e terceira versão da Base Nacional Comum Curricular (BNCC) para os anos finais do Ensino Fundamental, especificamente na área de Ciências da Natureza. Para isso, realizamos uma análise documental e discutimos as diferentes abordagens da Educação Ambiental nas duas versões dos documentos. Esse estudo pretende destacar a relevância que essa temática possui, ao propiciar a formação de cidadãos críticos e participativos, além das crescentes demandas em relação à melhoria da qualidade de vida, ao consumo consciente e à preservação do meio ambiente. Porém, ao investigarmos a abordagem da Educação Ambiental na BNCC, percebemos certos reducionismos, tendo predomínio das questões voltadas às perspectivas ecológicas. Desse modo, observamos que não houve um avanço significativo para o fortalecimento da Educação Ambiental no currículo da disciplina escolar Ciências.

Palavras-chave: Base Nacional Comum Curricular, Ciências, Educação Ambiental.

\section{El enfoque de la Educación Ambiental en la segunda y tercera versión de la Base Curricular Nacional Común}

Resumen: Este artículo tiene como objetivo analizar el enfoque de la Educación Ambiental en la segunda y tercera versión de las Bases Curriculares Nacionales Comunes (BNCC) para los primeros años de la educación pre-universitaria, específicamente en el área de Ciencias de la Naturaleza. Para ello, realizamos un análisis de

\footnotetext{
1 Licenciatura em Ciências Biológicas pela Universidade Estadual do Sudoeste da Bahia (UESB). E-mail: mariana.bittencourt27@gmail.com

${ }^{2}$ Doutor em Educação. Professor do Programa de Pós-Graduação em Educação e do Departamento de Ciências Naturais (DCN) da Universidade Estadual do Sudoeste da Bahia (UESB). E-mail: medeirosed@uesb.edu.br
} 
los documentos y discutimos los diferentes enfoques de la Educación Ambiental en ambas versiones de los documentos. Este estudio pretende destacar la relevancia de este tema para fomentar la formación de ciudadanos críticos y participativos, además de las crecientes demandas en relación con la mejora de la calidad de vida, el consumo consciente y la preservación del medio ambiente. Sin embargo, al investigar el enfoque de la Educación Ambiental en el BNCC, notamos cierto reduccionismo, existiendo un predominio de temas enfocados en perspectivas ecológicas. Observamos por lo tanto, que no hubo avances significativos para el fortalecimiento de la Educación Ambiental en el currículo de la asignatura de Ciencias en esta etapa formativa. Palabras-clave: Base Curricular Nacional Común, Ciencias, Educación ambiental.

\title{
Environmental education approaches of the second and third version of the Common Core National Curriculum
}

\begin{abstract}
This article aims to analyze the environmental education approach of the second and third version of the Common Core National Curriculum (BNCC) for the natural sciences area of the lower years of the elementary school. For this, a document analysis has been made to discuss different approaches of the environmental education in both versions. This study highlights the relevance of this topic, as it fosters the education of critical and participatory citizens. In addition, a critical environmental education meets the growing demands for improving the quality of life, conscious consumption and environmental protection. The research of these environmental education approaches in the BNCC shows reductionism and predominance of issues from ecological perspectives. Therefore, the research shows that little progress has been made to strengthen environmental education in the current sciences curriculum.
\end{abstract}

Keywords: National Common Core Curriculum, Sciences school curriculum, Environmental Education.

\section{Introdução}

A proposta de elaboração de um currículo nacional não é recente, uma vez que ela foi iniciada com a Constituição de 1988, quando já se falava de “[...] conteúdos mínimos para o Ensino Fundamental, de maneira a assegurar formação básica comum e respeito aos valores culturais e artísticos nacionais e regionais" (BRASIL, 1988, artigo 210, capítulo III). Depois disso, a Lei de Diretrizes e Bases da Educação Nacional (LDB), promulgada em 1996, no capítulo II, artigo 26 mostrava a demanda por uma "[...] base nacional comum, a ser complementada, em cada sistema de ensino e em cada estabelecimento escolar" (BRASIL, 1996).

Em 2014, no Plano Nacional de Educação (PNE), é renovada essa ideia da necessidade de uma base, com isso, entre as metas estabelecidas para a melhoria da Educação Básica, algumas faziam referência a uma Base Nacional Comum Curricular (BNCC). Desse modo, esse documento normativo começou a ser preparado em 2015, com a participação de especialistas e profissionais do ensino, visando à aplicação dos conteúdos que devem ser 
aprendidos pelos alunos em nível nacional. Segundo Gonçalves, Machado e Correia (2020), até 2016 houve lugar para debates com participação da sociedade. Porém, após o afastamento da presidenta Dilma, houve um apressamento, de modo que ocorreu a aprovação da versão final do documento em pouco mais de um ano. Assim, em 2017, foi homologada sua terceira e última versão para a Educação Infantil e o Ensino Fundamental e, em 2018, foi homologada a versão referente ao Ensino Médio. Hoje, temos uma Base que vai desde a Educação Infantil até o Ensino Médio, contemplando toda a Educação Básica.

Cabe considerar que a produção da BNCC foi marcada por um período de crise econômica e política, havendo debates e críticas em torno de sua elaboração por parte de professores, especialistas e associações acadêmicas, já que sua versão final foi publicada sem um tempo maior para comunicação e discussão das propostas. Por se tratar de um campo de disputas, de um lado temos os que lutam e defendem uma educação justa e de qualidade para todos, que contribua para superação das injustiças sociais; de outro, os que defendem a transformação da educação em um instrumento de dominação, fazendo com que os indivíduos aceitem como natural as suas diferenças econômicas, sociais e culturais.

Nesse contexto, é possível notar que a formação crítica e emancipatória foi perdendo espaço no campo educacional, visto que a BNCC direciona os interesses de aprendizagem para atender ao mercado de trabalho, cujo objetivo é formar indivíduos que forneçam mão de obra barata e flexível e que se adaptem de maneira mais fácil a diferentes situações. Em vista disso, o estabelecimento da BNCC não tem como função principal a solução de problemas da educação, questões sociais ou melhoria do ensino, mas atender aos interesses políticos e às demandas econômicas (BRANCO et al. 2018).

Ao tomar estas considerações no campo do currículo, Sacristán (2000, p. 17) adverte que as forças políticas e econômicas têm influência na formação dos currículos em seus conteúdos e na forma de desenvolvê-los. Dessa forma, o currículo representa o antagonismo de interesses dentro de uma sociedade e os valores dominantes que regem os processos educativos, ele é, portanto, “[...] a expressão do equilíbrio de interesses e forças que gravitam sobre o sistema educativo num dado momento". Assim, na constituição da BNCC percebemos uma redução de conteúdos e menor destaque para as questões sociais. 
Embora o documento destaque que a construção da Base ocorreu com a influência e a participação de diversos segmentos e atores, conforme destaca Ball (1994) apud Lopes e Macedo (2011a, p. 258), a participação desses segmentos na elaboração de uma dada política curricular "[...] não significa [...] que todas as vozes são ouvidas na polifonia do texto curricular, na medida que há posições legitimadas e outras não. No interior do que poderia ser chamado de posições legitimadas, ainda há uma pluralidade de grupos em disputa".

Nesse sentido, a produção da BNCC expressa esse espaço de disputas. A análise desse contexto evidencia que o currículo é um campo de lutas e relações de poder, pois os conhecimentos ensinados nas escolas "[...] são construções sociais que atendem a determinadas finalidades da educação e, por isso, reúnem sujeitos em determinados territórios, sustentam e são sustentadas por relações de poder que produzem saberes" (LOPES; MACEDO, 2011b, p. 121). Assim, a análise de sua implementação pressupõe considerar as perspectivas e construtos dos campos das políticas públicas da educação e dos estudos do currículo.

Ao analisar a BNCC, tomando com aporte os referenciais do campo do currículo, cabe considerar que definição(ões) de currículo está(ão) subjacentes a este documento, por isso, vale nos perguntarmos não somente "o que" está na BNCC, mas "por que este conhecimento e não outro" (SILVA, 2005, p. 158-159). Segundo o próprio texto, a BNCC é “[...] um documento de caráter normativo que define o conjunto orgânico e progressivo de aprendizagens essenciais que todos os alunos devem desenvolver ao longo das etapas e modalidades da Educação Básica" (BRASIL, 2018, p. 7). No entanto, Franco e Munford (2018, p. 167) destacam que, em carta encaminhada ao CNE pela Associação Brasileira de Currículo, esta associação “[...] problematiza a própria noção de 'base' presente versão atual: uma base seria aquilo sobre o qual se constrói algo, porém, o que temos com a BNCC são definições de onde se quer chegar (competências)".

Deste modo, fundamentado na pedagogia das competências, o referido documento visa a normatizar a aplicação dos conteúdos que devem ser aprendidos pelos alunos em âmbito nacional, tendo assim, uma perspectiva de unificação. Contudo, é preciso considerar que, num país de dimensões continentais como o Brasil, até que ponto a perspectiva de

Revista Eletrônica do Mestrado em Educação Ambiental Programa de Pós-Graduação em Educação Ambiental - FURG v. 38, n.2, p. 200-216, mai./ago. 2021. E-ISSN: 1517-1256 
unificação não estaria secundarizando a diversidade social, cultural e econômica que vivemos. Além disso, é preciso avaliar também a concepção de currículo que está por trás das prescrições trazidas pela BNCC.

Ainda merece destacar que, por estar estruturada no desenvolvimento de competências atreladas a um conjunto de habilidades que os alunos devem adquirir, estas, muitas vezes, não favorecem que os indivíduos percebam a realidade de forma crítica para promover uma transformação. Nesse sentido, em muitas dessas competências e habilidades observamos uma visão voltada à preparação para o mercado de trabalho. Cunha e Lopes (2017) analisam a BNCC como um guia que limita a educação, as relações e os sujeitos a algo que já foi previamente determinado pelas experiências avaliadas como mais adequadas. Assim, faz-se presente uma concepção limitada de currículo, na qual as diferenças são deixadas de lado.

Dessa forma, tendo em vista o contexto político e a formulação de um currículo que vai de encontro ao desenvolvimento crítico dos estudantes e, considerando que alguns temas foram foco de intensas disputas na formulação desse documento, como por exemplo as questões de sexualidade e gênero, assim ocorreu, também, com a Educação Ambiental.

Nesse sentido, podemos perceber a relevância que esse tema possui, uma vez que tem o papel de incentivar pensamentos e práticas conscientes e transformadoras, além de desenvolver cidadãos críticos e participativos. Segundo Reigota $(2008$, p. 6), a Educação Ambiental deve ser pensada e compreendida como uma educação política, pois "[...] ela reivindica e prepara os cidadãos e as cidadãs para exigir e construir uma sociedade com justiça social, cidadanias (nacional e planetária), autogestão e ética nas relações sociais e com a natureza".

Desse modo, são necessárias iniciativas em busca de uma melhor abordagem das questões ambientais na organização curricular das escolas, para superar uma Educação Ambiental fragmentada e reducionista que aposte na inovação dos conteúdos e se relacione com a vida cotidiana dos alunos por meio do diálogo. Assim, esse artigo busca investigar as abordagens da Educação Ambiental na segunda e terceira versão da BNCC para a área de Ciências da Natureza nos anos finais do Ensino Fundamental. 


\section{Aspectos metodológicos}

A metodologia desse trabalho está fundamentada em uma análise documental. Segundo Pimentel (2001, p. 180), "Estudos baseados em documentos como material primordial [...] extraem deles toda a análise, organizando-os e interpretando-os segundo os objetivos da investigação proposta". Desse modo, a análise documental tem como propósito investigar, em documentos, informações que possam contribuir para a análise da questão de pesquisa em foco. Cabe destacar que os documentos "[...] não são apenas uma fonte de informação contextualizada, mas surgem num determinado contexto e fornecem informação sobre esse mesmo contexto" (LÜDKE; ANDRÉ, 1986, p. 39).

Diante disso, foi realizada uma análise da abordagem da Educação Ambiental proposta pela BNCC para a disciplina escolar Ciências nos finais do Ensino Fundamental, com o intuito de avaliar os avanços e os retrocessos da temática na segunda e na terceira versão da Base.

\section{A Educação Ambiental na Base Nacional Comum Curricular: interfaces da segunda e terceira versão com a disciplina escolar Ciências}

Na segunda versão, publicada em 2016, a área de Ciências da Natureza apresenta cinco unidades de conhecimento a serem estudadas do sexto ao nono ano do Ensino Fundamental, a saber: Materiais, Propriedades e Transformações; Ambiente, Recursos e Responsabilidades; Terra: Constituição e Movimento; Vida: Constituição e Evolução; Sentidos, Percepção e Interações.

A unidade "Ambiente, Recursos e Responsabilidades" propõe habilidades voltadas diretamente às questões ambientais, aos recursos naturais e à responsabilidade no seu uso. Desse modo, essa unidade intenciona promover conhecimentos que contribuam para a preservação e a conscientização por parte dos alunos. O documento ressalta que se deve 
promover uma "[...] Educação Ambiental que favoreça a participação na construção de sociedades sustentáveis" (BRASIL, 2016, p. 442).

Essa segunda versão traz temas que, de acordo com o texto, podem contribuir para um equilíbrio ambiental, promover uma percepção sobre os impactos ambientais e os efeitos no organismo humano, causados pelo desmatamento, queimada e uso de combustíveis fosseis. Aborda, ainda, temas como tecnologias relacionadas à melhoria da qualidade de vida, apresentados em habilidades distribuídas ao longo dos anos finais do Ensino Fundamental. No texto, essa unidade de conhecimento também propõe uma reflexão sobre padrões de consumo e a estrutura econômica atual, para tanto, afirma: "Com essa unidade, procura-se responder a questões como: qual a relação existente entre o consumo humano e a disponibilidade de recursos naturais? Qual a relação existente entre modelo de desenvolvimento econômico, padrões de consumo humano e sustentabilidade? [...]" (BRASIL, 2016, p. 443).

Porém, essas questões propostas não estão presentes nos objetivos de aprendizagem. O que vemos são objetivos que aparecem de forma fragmentada, pois, em se tratando da área de Ciências da Natureza, a Educação Ambiental só está presente nessa unidade de conhecimento que se destina ao estudo do ambiente, não se fazendo presente nas demais. Além disso, os objetivos estão restritos à visão ecológica, conforme pode ser visto nas habilidades do sexto e sétimo ano:

(EF06Cl03) Investigar a interdependência entre os ciclos naturais da água (superficial e subterrâneo) e o padrão de circulação atmosférica e sua importância para formação de solos e da vida na Terra, e seu papel em mudanças climáticas atuais (BRASIL, 2016, p. 442).

(EF07Cl03) Produzir um diagrama que apresente fluxos de energia e matéria nos ecossistemas, mostrando as relações entre cadeias alimentares e teias alimentares (BRASIL, 2016, p. 442).

(EF07CI04) Relacionar a fotossíntese, a respiração celular e a combustão nos ciclos do carbono e do oxigênio para compreender o papel da vegetação na vida humana e animal, e discutir o impacto ambiental do desmatamento e das queimadas (BRASIL, 2016, p. 442). 
Desse modo, essas questões vão de encontro ao que o documento propõe ao considerar a Educação Ambiental como um tema especial,

\begin{abstract}
Esses temas dizem respeito a questões que atravessam as experiências dos sujeitos em seus contextos de vida e atuação e que, portanto, intervêm em seus processos de construção de identidade e no modo como interagem com outros sujeitos e com o ambiente, posicionando-se ética e criticamente sobre e no mundo (BRASIL, 2016, p. 47).
\end{abstract}

Assim, esse tema possui relevância social e deve ser trabalhado de forma contextualizada, portanto, deve estar presente nos objetivos de aprendizagem dos diversos componentes curriculares, articulando visões sociais, econômicas, políticas, éticas etc., por meio da reflexão. Entretanto, na BNCC, especificamente na disciplina escolar Ciências, não é o que percebemos. A inserção de conteúdos socioambientais é mínima e os objetivos de aprendizagem não favorecem a abordagem do potencial crítico que a temática possui.

Na terceira versão da BNCC, publicada em 2018, houve uma redução das temáticas para a área de Ciências da Natureza, sendo elas: Matéria e Energia; Vida e Evolução; Terra e Universo. De acordo com o próprio texto da Base, "[...] essas três unidades temáticas devem ser consideradas sob a perspectiva da continuidade das aprendizagens e da integração com seus objetos de conhecimento ao longo dos anos de escolarização" (BRASIL, 2018, p. 329). Dessa forma, temas como a sustentabilidade socioambiental, o ambiente, a saúde e a tecnologia são desenvolvidos nas três unidades temáticas. Assim, percebemos que, ao contrário da segunda versão, não se usa o termo Educação Ambiental propriamente dito, estando subentendido em certas habilidades. A única vez que o termo aparece é na introdução do documento, referindo-se a um dos temas que devem ser incorporados nos currículos e nas propostas pedagógicas, preferencialmente de forma transversal (BRASIL, 2018).

Nessa versão homologada, a Educação Ambiental é proposta como um tema contemporâneo, em que se abandona a terminologia "tema especial", adotada na segunda versão. Com isso, cabe às escolas e redes de ensino "[...] incorporar aos currículos e às propostas pedagógicas a abordagem de temas contemporâneos que afetam a vida humana 
em escala local, regional e global, preferencialmente de forma transversal e integradora" (BRASIL, 2018, p. 19).

Desta forma, o propósito é semelhante ao dos temas especiais da segunda versão, devendo perpassar os diversos componentes curriculares de forma integradora e promover reflexões sobre temas que são relevantes para sua atuação na sociedade, para que eles possam pensar de forma consciente e crítica, propiciando a resolução de problemas. 0 documento também destaca que, os alunos "[...] além de entenderem a importância da biodiversidade para a manutenção dos ecossistemas e do equilíbrio dinâmico socioambiental, sejam capazes de avaliar hábitos de consumo que envolvam recursos naturais e artificiais [...]" (BRASIL, 2018, p. 329).

Contudo, mais uma vez, ao analisarmos as habilidades do sétimo, oitavo e nono ano, percebemos que a Educação Ambiental é abordada numa perspectiva ecológica e não remete à ideia de integração entre as unidades temáticas, conforme o documento se propõe fazer.

(EF07Cl08) Avaliar como os impactos provocados por catástrofes naturais ou mudanças nos componentes físicos, biológicos ou sociais de um ecossistema afetam suas populações, podendo ameaçar ou provocar a extinção de espécies, alteração de hábitos, migração etc. (BRASIL, 2018, p. 347).

(EF07CI07) Caracterizar os principais ecossistemas brasileiros quanto à paisagem, à quantidade de água, ao tipo de solo, à disponibilidade de luz solar, à temperatura etc., correlacionando essas características à flora e fauna específicas (BRASIL, 2018, p. 347).

(EF08CI06) Discutir e avaliar usinas de geração de energia elétrica (termelétricas, hidrelétricas, eólicas etc.), suas semelhanças e diferenças, seus impactos socioambientais, e como essa energia chega e é usada em sua cidade, comunidade, casa ou escola (BRASIL, 2018, p. 349).

EF09CI12) Justificar a importância das unidades de conservação para a preservação da biodiversidade e do patrimônio nacional, considerando os diferentes tipos de unidades (parques, reservas e florestas nacionais), as populações humanas e as atividades a eles relacionados (BRASIL, 2018, p. 351).

Reigota (2008) adverte que é fundamental não relacionarmos a Educação Ambiental somente aos aspectos da ecologia biológica. Por mais que as questões associadas à proteção 
e conservação de espécies e recursos naturais sejam importantes, não devemos deixar de considerar os aspectos políticos e sociais. O autor ressalta que, na Educação Ambiental, é imprescindível a análise das relações "[...] políticas, econômicas, sociais e culturais entre a humanidade e a natureza e as relações entre os seres humanos, visando a superação dos mecanismos de controle e de dominação que impedem a participação livre, consciente e democrática de todos" (REIGOTA, 2008, p. 5)

Apesar disso, cabe destacar que na terceira versão da BNCC não há avanço em relação à versão anterior. Embora com pouca ênfase, percebemos certas habilidades que propõem desenvolver nos alunos uma conscientização, inclusive, em relação a padrões de consumo, conforme pode ser observado nas habilidades para o oitavo e nono ano:

(EF08CI05) Propor ações coletivas para otimizar o uso de energia elétrica em sua escola e/ou comunidade, com base na seleção de equipamentos segundo critérios de sustentabilidade (consumo de energia e eficiência energética) e hábitos de consumo responsável (BRASIL, 2018, p. 349).

(EF09Cl13) Propor iniciativas individuais e coletivas para a solução de problemas ambientais da cidade ou da comunidade, com base na análise de ações de consumo consciente e de sustentabilidade bem-sucedidas (BRASIL, 2018, p. 351).

Dessa forma, na terceira versão, a intenção é dar um destaque maior à sustentabilidade socioambiental, de modo que há um "[...] incentivo à proposição e adoção de alternativas individuais e coletivas, ancoradas na aplicação do conhecimento científico, que concorram para a sustentabilidade socioambiental" (BRASIL, 2018, p. 327). Porém, mesmo considerando essa questão, não foram verificadas mudanças significativas da segunda para a terceira versão. Por mais que a última versão apresente um número maior de habilidades relacionadas à temática ambiental, ocorrem alguns reducionismos em relação à Educação Ambiental.

$\mathrm{Na}$ terceira versão, as questões ambientais não se expressam de modo claro, como na segunda versão, o que representa um retrocesso, pois a segunda possuía uma unidade de conhecimento voltada exclusivamente para essa temática. Desse modo, na terceira, a Educação Ambiental encontra-se de maneira implícita nas habilidades presentes ao longo 
das unidades temáticas, perdendo espaço para a abordagem do tema de forma mais abrangente. No sexto ano, por exemplo, entre as quatorze habilidades apresentadas, a única que podemos observar uma aproximação com a Educação Ambiental é a que propõe “(EF06Cl04) Associar a produção de medicamentos e outros materiais sintéticos ao desenvolvimento científico e tecnológico, reconhecendo benefícios e avaliando impactos socioambientais" (BRASIL, 2018, p. 345). Portanto, só encontramos aspectos relacionados a esse tema na unidade temática "Matéria e Energia", contrariando o que a Base indica ao considerar que temas como esse deveriam estar presentes em todas as unidades temáticas.

Assim, a análise documental realizada permite destacar que, na BNCC, a Educação Ambiental não possui a visibilidade, como possuía nos Parâmetros Curriculares Nacionais (PCN). Mesmo sendo um tema contemporâneo que deve ser incorporado ao currículo de forma transversal, a inserção desse tema não é expressiva.

Podemos perceber que nas duas versões a Educação Ambiental está circunscrita a uma visão ecológica. Na segunda versão ela aparece associada a conteúdos como fotossíntese, cadeias alimentares, ciclos biogeoquímicos e na terceira apresenta aspectos relacionados à sustentabilidade, ao propor certas habilidades que têm a intenção de conscientizar sobre o uso de energia elétrica e hábitos de consumo, no entanto, é limitada a abordagem dos aspectos sociais, econômicos, culturais e políticos. A inserção desse tema apresenta reducionismos em debates envolvendo os reais problemas ambientais que vivemos, os impactos socioambientais causados pela relação desarmônica da sociedade com o meio ambiente, o modelo econômico capitalista adotado e suas consequências, as questões relacionadas ao consumo desenfreado, a produção excessiva de produtos e a acumulação de lixo, entre outros que tornam a Educação Ambiental um tema necessário.

Segundo Sorrentino et al. (2005, p. 287), "A urgente transformação social de que trata a educação ambiental visa à superação das injustiças ambientais, da desigualdade social, da apropriação capitalista e funcionalista da natureza e da própria humanidade". Os autores ressaltam também que "A educação ambiental, em específico, ao educar para a cidadania, pode construir a possibilidade da ação política, no sentido de contribuir para 
formar uma coletividade que é responsável pelo mundo que habita" (SORRENTINO et al., 2005, p. 287).

Ainda acrescentam que a Educação Ambiental deve buscar, por meio de uma ação coletiva, a superação dos problemas ambientais, entendendo que, por estarem intimamente relacionadas, natureza e sociedade não podem ser pensadas de forma separada (SORRENTINO et al., 2005). Assim sendo, os indivíduos devem obter conhecimentos e valores que contribuam para a conservação do meio ambiente. Porém, na BNCC, as questões e problemas ambientais são tratados de forma tangencial e não explicita intenções para tomada de decisão política, o que pode limitar ainda mais a abordagem desse tema na educação escolar.

Sabemos da importância ao acesso a conhecimentos que proporcionem uma participação em questões que interferem nas nossas vidas, o que torna necessária uma educação mais efetiva e atenta à superação de suas demandas. Por se tratar de um tema que deve ser incorporado de maneira transversal, a Educação Ambiental é indispensável para a formação da consciência dos estudantes, deve, portanto, ser trabalhada de modo contextualizado, visando a superar a fragmentação no processo de ensino.

Cabe considerar que, segundo Guimarães (2016), no Brasil, o movimento ambientalista começou a ganhar notoriedade a partir da década de 1980 com ações e movimentos militantes que pretendiam disseminar seus ideais ambientalistas. A Constituição Federal de 1988 já indicava a necessidade do poder público de promover a Educação Ambiental em todos os níveis de ensino. Posteriormente, no período da Rio 92 sobre Meio Ambiente e Desenvolvimento, ocorreram as primeiras iniciativas próximas às secretarias de educação e ao Ministério da Educação (MEC). Desde essa época, a Educação Ambiental já era vista como um meio de possibilitar reflexões, debates e aprendizagens para promover o respeito a todas as formas de vida.

A Lei da Educação Ambiental de 1999, em seu artigo 1, coloca a Educação Ambiental como um processo, no qual os indivíduos "[...] constroem valores sociais, conhecimentos, habilidades, atitudes e competências voltadas para a conservação do meio ambiente, bem 
de uso comum do povo, essencial à sadia qualidade de vida e sua sustentabilidade" (BRASIL, 1999).

Já as Diretrizes Curriculares Nacionais para a Educação Ambiental, em seu artigo $2^{\circ}$, diz que a Educação Ambiental é uma

[...] dimensão da educação, é atividade intencional da prática social, que deve imprimir ao desenvolvimento individual um caráter social em sua relação com a natureza e com os outros seres humanos, visando potencializar essa atividade humana com a finalidade de torná-la plena de prática social e de ética ambiental (BRASIL, 2012, p. 2).

Porém, ao mesmo tempo em que se fala e se ressalta o mérito da Educação Ambiental, reconhece-se a necessidade de superações nessa área, e mesmo sendo um campo de conhecimento que vem crescendo ao longo da história - mediante a realização de conferências, encontros, reuniões e movimentos, cuja pautas estão presentes em documentos fundamentais, legais e norteadores - a Educação Ambiental é tratada de forma superficial na BNCC. Desse modo, nas escolas, da forma como a Base propõe, a Educação Ambiental ainda estará distante de se manifestar de forma concreta, apresentando resultados pouco significativos.

De acordo com Guimarães (2016), a Educação Ambiental pode refletir diferentes visões de mundo, podendo ter uma perspectiva mais conservadora ou mais crítica. A conservadora possui práticas que mantém o atual modelo de sociedade, dessa forma, a transformação viria em face da vontade de cada indivíduo, já que as relações sociais perdem relevância, o foco passa a ser a mudança individual. Já a visão crítica envolve processos que provocam transformações na sociedade, buscando um equilíbrio socioambiental. Ainda segundo Guimarães (2016, p. 17), "Aqui a compreensão e atuação sobre as relações de poder que permeiam e estruturam a sociedade são priorizados, significando uma Educação política, a qual nos faz perceber e ser os sujeitos que somos na história". Desse modo, segundo o autor, essas duas visões travam um embate, uma buscando melhor qualidade de vida, igualdade social e, consequentemente, uma melhor qualidade ambiental, e a outra é comprometida com os interesses do capital e do mercado. 
Reigota (2008), considerando a Educação Ambiental como uma educação política, diz que ela tem o compromisso de despertar a cidadania e a autonomia dos indivíduos para que eles busquem caminhos para um bem comum, em que se respeite todas as formas de vida, reivindique uma sociedade mais justa, mais ética nas relações sociais e com a natureza, questione as ações políticas e se posicione contra todo tipo de corrupção. A Educação Ambiental ainda deve propiciar o entendimento de que somos elementos da natureza e não seres superiores que possuem vantagens em função da sua exploração.

O autor ainda ressalta que a Educação Ambiental não irá resolver todos os problemas ambientais do mundo, mas ela pode influenciar e inspirar para que isso aconteça, formando cidadãos conscientes dos seus direitos e deveres. Por consequência, "A Educação Ambiental crítica está, dessa forma, impregnada da utopia de mudar radicalmente as relações que conhecemos hoje, sejam elas entre a humanidade, sejam elas entre a humanidade e a natureza" (REIGOTA, 2008, p. 9).

Em vista disso, percebemos que a Educação Ambiental, pelo seu potencial reflexivo, é um tema que tem um papel transformador para o questionamento das relações sociais, denunciando o que não é interessante para uma política voltada ao distanciamento crítico da educação. Assim, ao analisarmos as questões referentes a essa temática na BNCC, percebemos um retrocesso, pois, apesar de a Base fazer menção a uma abordagem crítica e reflexiva, essas questões não se fazem tão presentes no documento, nos objetos de conhecimento (conteúdos), nem nas competências e habilidades propostas. Desse modo, as questões ambientais presentes na BNCC não demonstram filiação com uma Educação Ambiental crítica e transformadora.

\section{Considerações finais}

Este estudo teve como finalidade a análise de como a Educação Ambiental é abordada na segunda e terceira versão da BNCC, especificamente, na área de Ciências da Natureza, nos anos finais do Ensino Fundamental. A análise permitiu perceber que, apesar de ser um campo em crescimento nos últimos anos e ter um percurso de lutas e conquistas, 
a Educação Ambiental perdeu espaço nesse documento, cujo predomínio foram das questões voltadas às perspectivas ecológicas, de modo que foram ocultados os debates dos problemas ambientais existentes.

Compreendemos a relevância desse tema e como ele é essencial, por isso, deve estar presente em todos os níveis educacionais, pois, ao promover uma problematização das relações sociais, éticas, tecnológicas, políticas e econômicas, a Educação Ambiental favorece o desenvolvimento crítico dos indivíduos. Porém, isso parece ter sido ignorado pela BNCC, pois a Educação Ambiental se apresenta de forma reduzida e fragmentada ao longo das unidades temáticas, o que permite inferir que, comparativamente, não houve um avanço significativo para o seu fortalecimento, mas um retrocesso.

Diante do tangenciamento das questões ambientais na BNCC, o papel dos professores se torna imprescindível para que a Educação Ambiental seja valorizada e garantida na Educação Básica. Assim, será possível propiciar aos alunos condições de participação nas questões que interferem na vida do planeta. Nesse sentido, cabe aos professores atuarem como mediadores de conhecimentos por meio de novas iniciativas, tencionado a estrutura curricular para superar o ensino de Ciências reducionista e fragmentado. Portanto, este é o desafio, promover mudanças nas formas de pensar e agir, tornando a Educação Ambiental, por meio da tomada de consciência dos alunos, um instrumento para a transformação da sociedade.

\section{Referências}

BRANCO, Emerson Pereira; BRANCO, Alessandra Batista de Godoi; IWASSE, Lilian Fávaro Alegrâncio; ZANATTA, Shalimar Calegari. Uma visão crítica sobre a implantação da Base Nacional Comum Curricular em consonância com a reforma do ensino médio. Revista Debates em Educação, Maceió, v. 10, n. 21, p. 47-70, 2018. Disponível em: https://www.seer.ufal.br/index.php/debateseducacao/article/view/5087 Acesso em: 26 abr. 2020.

BRASIL. Base Nacional Comum Curricular (BNCC). Educação é a Base. Brasília, MEC/CONSED/UNDIME, 2018. Disponível:

Revista Eletrônica do Mestrado em Educação Ambiental Programa de Pós-Graduação em Educação Ambiental - FURG v. 38, n.2, p. 200-216, mai./ago. 2021. E-ISSN: 1517-1256 
http://basenacionalcomum.mec.gov.br/images/BNCC El EF 110518 versaofinal site.pdf Acesso em: 26 abr. 2020.

BRASIL. Base Nacional Comum Curricular - proposta preliminar segunda versão revista. MEC/CONSED/UNDIME, 2016. Disponível em: http://portal.mec.gov.br/docman/maio-2016pdf/40791-bncc-proposta-preliminar-segunda-versao-pdf/file Acesso em: 26 abr. 2020.

BRASIL. Ministério da Educação. Diretrizes Curriculares Nacionais para a Educação

Ambiental. Brasília: Ministério da Educação /Conselho Nacional de Educação, 2012. Disponível em: http://portal.mec.gov.br/dmdocuments/rcp002 12.pdf Acesso em: 28 abr. 2020.

BRASIL. Lei n. 9.795, de 27 de abril de 1999. Dispõe sobre a educação ambiental, institui a Política Nacional de Educação Ambiental e dá outras providências. Brasília, 1999. Disponível em:

https://www.camara.leg.br/proposicoesWeb/prop mostrarintegra;isessionid=50EE32BD99A F52EB7D5DB8E7E03AE765.node1 ?codteor $=634068 \&$ filename $=$ LegislacaoCitada+PL+4692/2009 Acesso em: 28 abr. 2020.

BRASIL. Lei no 9.394, de 20 de dezembro de 1996. Estabelece as diretrizes e bases da educação nacional. Disponível em: http://www.planalto.gov.br/ccivil 03/leis/L9394.htm Acesso em: 28 abr. 2020.

BRASIL. [Constituição (1988)]. Constituição da República Federativa do Brasil. Brasília, DF: Presidência da República, [2016]. Disponível em:

http://www.planalto.gov.br/ccivil 03/Constituicao/Constituiçao.htm Acesso em: 28 abr. 2020.

CUNHA, Érika Virgílio Rodrigues da; LOPEZ, Alice Casimiro. Base Nacional Comum Curricular no Brasil: regularidade na dispersão. Investigación Cualitativa, Brasil, v. 2, n. 2, p. 23-35, 2017. Disponível em: http://abrapecnet.org.br/wordpress/wpcontent/uploads/2018/05/CunhaLopes2017.pdf Acesso em: 25 abr. 2020.

FRANCO, Luiz Gustavo; MUNFORD, Danusa. Reflexões sobre a Base Nacional Comum Curricular: Um olhar da área de Ciências da Natureza. Horizontes, Itatiba, v. 36, n. 1, p. 144157, jan./abr. 2018. Disponível em:

https://revistahorizontes.usf.edu.br/horizontes/article/view/582 Acesso em: 25 fev. 2020.

GONÇALVES, Rafael Marques; MACHADO, Tânia Mara Rezende; CORREIA, Maria José Nascimento. A BNCC na contramão das demandas sociais: Planejamento com e planejamento para. Revista Práxis Educacional, Vitória da Conquista, v. 16, n. 38, p. 338351, jan./mar. 2020. Disponível em: https://periodicos2.uesb.br/index.php/praxis/article/view/6012 Acesso em: 26 maio 2020. 
GUIMARÃES, Mauro. Por uma educação ambiental crítica na sociedade atual. Revista Margens, Rio de Janeiro, v. 7, n. 9, p. 11-22, maio 2016. Disponível em: https://periodicos.ufpa.br/index.php/revistamargens/article/view/2767/2898 Acesso em: 22 maio 2020.

LOPES, Alice Casimiro; MACEDO, Elizabeth. Contribuições de Stphen Ball para o estudo de Políticas de Currículo. In: BALL, Stephen; MAINARDES, Jefferson (Org.). Políticas Educacionais: questões e dilemas. São Paulo: Cortez, 2011a.

LOPES, Alice Casimiro; MACEDO, Elizabeth. Teorias de currículo. São Paulo: Cortez. 2011b.

LÜDKE, Menga; ANDRÉ, Marli E. D. A. Pesquisa em educação: abordagens qualitativas. São Paulo: EPU, 1986.

PIMENTEL, Alessandra. O método da análise documental: seu uso numa pesquisa historiográfica. Cadernos de Pesquisa, Londrina, n. 114, p. 179-195, nov. 2001. Disponível em: https://www.scielo.br/pdf/cp/n114/a08n114.pdf Acesso em: 29 abr. 2020.

REIGOTA, Marcos. O que é educação ambiental. São Paulo: Brasiliense, 2008.

SACRISTÁN, J. G. O currículo: uma reflexão sobre a prática. Porto Alegre: Artmed, 2000.

SILVA, Tomaz Tadeu da. Documentos de Identidade: uma introdução às teorias do currículo. Belo Horizonte: Autêntica, 2005.

SORRENTINO, Marcos; TRAIBER, Rachel; MENDONÇA, Patrícia; FERRARO JÚNIOR, Luiz Antonio. Educação ambiental como política pública. Revista Educação e Pesquisa, São Paulo, v. 31, n. 2, p. 285-299, maio/ago. 2005. Disponível em:

https://www.scielo.br/pdf/ep/v31n2/a10v31n2.pdf Acesso em: 27 maio 2020. 